\title{
A Pilot Longitudinal Evaluation of MicroRNAs for Monitoring the Cognitive Impairment in Pediatric Multiple Sclerosis
}

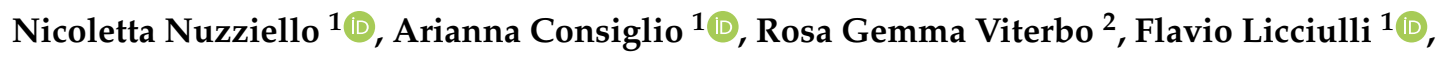 \\ Sabino Liuni ${ }^{1}\left(\mathbb{D}\right.$, Maria Trojano ${ }^{2}$ and Maria Liguori ${ }^{1, *(1)}$ \\ 1 National Research Council of Italy, Institute of Biomedical Technologies, Bari Section, 70125 Bari, Italy; \\ nicoletta.nuzziello@gmail.com (N.N.); arianna.consiglio@ba.itb.cnr.it (A.C.); \\ flavio.licciulli@ba.itb.cnr.it (F.L.); sabino.liuni@ba.itb.cnr.it (S.L.) \\ 2 Department of Basic Sciences, Neurosciences and Sense Organs, University of Bari, 70121 Bari, Italy; \\ rgviterbo@uniba.it (R.G.V.); mstojano@uniba.it (M.T.) \\ * Correspondence: maria.liguori@cnr.it; Tel.: +39-080-592-9663; Fax: +39-080-592-9690
}

Received: 30 September 2020; Accepted: 20 November 2020; Published: 22 November 2020

\begin{abstract}
MicroRNAs (miRNAs), a class of non-coding RNAs, seem to play a key role in complex diseases like multiple sclerosis (MS), as well as in many cognitive functions associated with the disease. In a previous cross-sectional evaluation on pediatric MS (PedMS) patients, the expression of some miRNAs and their target genes were found to be associated with the scores of some neuropsychiatric tests, thus suggesting that they may be involved in early processes of cognitive impairment. To verify these data, we asked the same patients to be re-evaluated after a 1-year interval; unfortunately, only nine of them agreed to this further clinical and molecular analysis. The main results showed that 13 differentially expressed miRNAs discriminated the two time-points. Among them, the expression of miR-182-5p, miR-320a-3p, miR-744-5p and miR-192-5p significantly correlated with the attention and information processing speed performances, whereas the expression of miR-182-5p, miR-451a, $\mathrm{miR}-4742-3 p$ and miR-320a-3p correlated with the expressive language performances. The analysis of mRNA expression uncovered 58 predicted and/or validated miRNA-target pairs, including 23 target genes, some of them already associated with cognitive impairment, such as the transducing beta like 1 X-linked receptor-1 gene (TBL1XR1), correlated to disorders of neurodevelopment; the Snf2 related CREBBP activator protein gene (SRCAP) that was found implicated in a rare form of dementia; and the glia maturation factor beta gene (GMFB), which has been reported to be implicated in neurodegeneration and neuroinflammation. No molecular pathways involving the most targeted genes survived the adjustment for multiple data. Although preliminary, these findings showed the feasibility of the methods also applied to longitudinal investigations, as well as the reliability of the obtained results. These findings should be confirmed in larger PedMS cohorts in order to identify early markers of cognitive impairment, towards which more efficient therapeutic efforts can be addressed.
\end{abstract}

Keywords: pediatric multiple sclerosis; microRNA; gene target; high-throughput next-generation sequencing

\section{Introduction}

Multiple sclerosis (MS) is a demyelinating autoimmune disease of the central nervous system (CNS) that usually affects young adults [1]. As in other complex multifactorial diseases, in MS the possibility to identify reliable biomarkers that are predictive of the disease course has so far been 
elusive due to the multifactorial nature of MS, which involves environmental factors, several genes and their epigenetic interactions [2]. Lately, the evidence that up to $5 \%$ of patients with MS experience their first clinical symptoms/signs before the age of 18 years [3] has offered the opportunity to investigate the very early steps of this heterogeneous disease, also helping to disentangle the complex molecular scenario of the latest phases and possibly leading to more targeted therapeutic efforts. To this aim, integrated approaches using deep sequencing technologies of next-generation sequencing (HT-NGS) provide valuable support, e.g., to assess the differential expression of microRNAs (miRNAs), which are epigenetic factors, the functions of which have been associated with MS and its phenotypic features [4].

Following these suggestions, in a previous study performed on a selected group of 19 pediatric MS (PedMS), 12 upregulated and 1 downregulated miRNAs resulted, compared to 20 age-matched controls [5]; six miRNAs were confirmed in an adult MS population $(n=58$ patients versus $n=20$ controls) suggesting that they may be considered as distinctive markers of the disease independently of their age [6]. It is also worth noting that the expression of 11 miRNAs correlated with the scores obtained in different cognitive tests; although none of them passed the 0.05 threshold of statistical significance, they seemed to point in the direction of a possible impact of miRNAs in PedMS cognitive performance [7].

To verify these findings, we asked the same PedMS population to be re-evaluated after 1-year by following the same clinical, neuropsychological and molecular protocols.

\section{Subjects and Methods}

The criteria for the recruitment of PedMS patients were detailed previously [5]. The study was approved by the Ethical Committee of Azienda Ospedaliera Policlinico, University of Bari. Since the PedMS patients were under the age of 18 , their legal guardians signed written informed consent forms (according to the Declaration of Helsinki) at the time of the evaluations.

For the clinical, molecular, bioinformatic and biostatistical analyses, we followed the same methods used for the first study [5]. Briefly, the clinical disability of each patient was scored by expanded disability status scale (EDSS) [8], whereas their neuropsychological performances were tested by a validated battery exploring several cognitive domains [9]. Peripheral blood samples of PedMS patients were collected in PAXgene blood RNA tubes, coded, anonymized and frozen at $-20^{\circ} \mathrm{C}$ until use. Total RNA was isolated using a PAXgene blood RNA kit (PreAnalytiX Qiagen/BD, Hilden, Germany) and sequenced by an Illumina HiSeq2500 platform, after the opportune processing of smallRNA (sRNA) and mRNA libraries. The HT-NGS data were analyzed with an integrated bioinformatics pipeline, developed by our group, that includes both miRNAs and genes expression estimation using mirDeep2, Bowtie, STAR and RSEM; differential expression analysis using edgeR and DESeq2; miRNA-target gene interaction evaluation using both experimentally validated microRNA-target interaction databases (DIANA-Tarbase and miRTarBase) and miRNA-target genes prediction algorithms (miRanda, RNAhybrid, RNA22, miRDB and TargetScan); pathway enrichment analysis using Database for Annotation, Visualization and Integrated Discovery (DAVID v6.8 https://david.ncifcrf.gov) tool that provides a large series of functional annotation tools and pathways databases, such as KEGG.

The EDSS score and the individual scores obtained by each administered neuropsychiatric test, at the study entry and after the follow-up period, were analyzed by a non-parametric Wilcoxon signed rank test for paired samples. Spearman's correlation test was also applied to miRNA expressions and to the scores of the cognitive tests.

\section{Results}

Only 9 out of 19 PedMS patients (3 males and 6 females) agreed to this further evaluation after a mean interval of $1.3 \pm 0.6 \mathrm{SD}$ years from the first exams (baseline demographic and clinical characteristics are summarized in Table 1A); five of them had started Interferon beta-1a (IFN $\beta-1 \mathrm{a})$ treatment in an average of 140 days (range $21-576$ days) from the study entry. 
The neuropsychiatric scores registered at the second time point suggested a trend to deterioration particularly in the domains of attention and information processing speed, visual-spatial memory, executive functioning and expressive language (Table 1B). However, no significant changes of clinical and cognitive abilities were recorded within the observational interval.

Table 1. A: demographic and clinical features of the investigated pediatric multiple sclerosis (PedMS) patients (at baseline). B: Mean scores $( \pm \mathrm{SD}$ ) obtained at the neuropsychiatric tests (baseline and follow-up).

\begin{tabular}{|c|c|c|}
\hline A. & & \\
\hline PedMS (No. 9) & \multicolumn{2}{|c|}{ Mean \pm SD } \\
\hline Age at onset (years) & \multicolumn{2}{|c|}{$14.1 \pm 2.1$} \\
\hline Disease duration (years) & \multicolumn{2}{|c|}{$2.2 \pm 2.0$} \\
\hline EDSS & \multicolumn{2}{|c|}{$2.7 \pm 0.9($ range $1.5-4.5)$} \\
\hline FSS & \multicolumn{2}{|c|}{$3.1 \pm 2.0$} \\
\hline CDI & \multicolumn{2}{|c|}{$5.4 \pm 1.8$} \\
\hline Schooling (years) & \multicolumn{2}{|c|}{$10.2 \pm 2.0$} \\
\hline \multicolumn{3}{|l|}{ B. } \\
\hline Cognitive Domains and Tests & $\begin{array}{c}\text { Baseline } \\
\text { (Mean } \pm \text { SD) }\end{array}$ & $\begin{array}{l}\text { Follow-Up } \\
(\text { Mean } \pm \text { SD) }\end{array}$ \\
\hline \multicolumn{3}{|l|}{ Verbal memory } \\
\hline SRT-LTS & $30.4 \pm 12$ & $30.8 \pm 10.8$ \\
\hline SRT-CLTR & $22 \pm 12.6$ & $23.6 \pm 11.2$ \\
\hline SRT-D & $6.7 \pm 2.2$ & $6.8 \pm 2.1$ \\
\hline \multicolumn{3}{|l|}{ Visual-spatial memory } \\
\hline SPART & $21 \pm 4.9$ & $20.6 \pm 3.2$ \\
\hline SPART-D & $7.3 \pm 2.2$ & $7.1 \pm 1.6$ \\
\hline \multicolumn{3}{|l|}{ Attention, IPS } \\
\hline SDMT & $40.9 \pm 7.9$ & $42.9 \pm 8.9$ \\
\hline TMT-A & $41.8 \pm 12.7$ & $41.8 \pm 11.8$ \\
\hline TMT-B & $97.4 \pm 46.3$ & $93.6 \pm 45.7$ \\
\hline \multicolumn{3}{|l|}{ Executive functioning } \\
\hline TOL & $25.4 \pm 5.2$ & $25 \pm 4.7$ \\
\hline \multicolumn{3}{|l|}{ Expressive language } \\
\hline SVFT & $24.6 \pm 10.6$ & $22.6 \pm 8.6$ \\
\hline PVFT & $15.6 \pm 5.7$ & $17.4 \pm 4.9$ \\
\hline
\end{tabular}

Abbreviations: EDSS = expanded disability status scale; FSS = fatigue severity scale; CDI = children depression inventory; IPS = information processing speed; SRT-LTS = selective reminding test long-term storage; SRT-CLTR = selective reminding test consistent long-term retrieval; SRT-D = selective reminding test-delayed; SPART = spatial recall test; SPART-D $=$ spatial recall test - delayed; $\mathrm{SDMT}=$ symbol digit modalities test; $\mathrm{TMT}=$ trail making test (TMT-A and TMT-B); TOL = Tower of London test; SVFT = semantic verbal fluency test $;$ PVFT $=$ phonemic verbal fluency test.

The multidimensional scaling (MSD) plot of dispersion index between the miRNA expressions of all PedMS subjects at baseline and at follow-up reported a definite separation between T0 and T12 that was due to 13 significantly differentially expressed (DE) miRNAs (adjusted $p$-value $<0.05$, absolute $\log 2$ fold change $>1$ ) (Table 2; Supplementary Figure S1). Since the clinical features of the examined PedMS patients did not significantly change during the interval, we could not verify whether any of 
these miRNAs might be considered as suggestive markers of the disease progression. However, it is interesting to note that the expression of miR-182-5p, miR-320a-3p, miR-744-5p and miR-192-5p significantly correlated with the scores at follow-up of the Trailing Making Test A (TMT-A) whereas the expression of miR-182-5p, miR-451a, miR-4742-3p and miR-320a-3p correlated with the scores obtained at the SVFT test (Spearman's rho correlation test, $p<0.05$; Supplementary Table S1 for details). Unfortunately, no adjustments for variables such as sex and concomitant Disease-Modifying Treatments (DMTs) (type and duration of treatment) were allowed due to the small sample size.

Table 2. miRNAs whose expression (logFC) results were statistically significantly different between the observational interval (adjusted $p$-value $<0.05$ ) and their published associations with MS and/or other neurodegenerative disorders.

\begin{tabular}{|c|c|c|c|}
\hline TRANSCRIPT ID & $\operatorname{LogFC}$ & $\begin{array}{l}\text { Adjusted } \\
p \text {-Value }\end{array}$ & $\begin{array}{l}\text { Reported Associations (References, See } \\
\text { Supplementary Files) }\end{array}$ \\
\hline hsa-miR-26b-5p & 2.254118 & 0.009 & $\begin{array}{l}\text { Upregulated in AD [10] } \\
\text { Upregulated in AD vs. FTD vs. HC [11] } \\
\text { Upregulated in ADHD [12] } \\
\text { Downregulated in SPMS [13] } \\
\text { Downregulated in AD [14] } \\
\text { Downregulated in ALS [15] } \\
\text { Related to A-beta expression in cortical neurons } \\
\text { animal model [16] }\end{array}$ \\
\hline hsa-miR-127-3p & -6.144506 & $<0.0001$ & $\begin{array}{l}\text { Downregulated in FTD [17] } \\
\text { Upregulated in PPMS exosomes [4] }\end{array}$ \\
\hline hsa-miR-182-5p & 1.341916 & 0.01 & $\begin{array}{l}\text { Upregulated in PedMS [5] } \\
\text { Downregulated in prion disease and AD [18] } \\
\text { Downregulated in ALS [19] } \\
\text { Inhibition of oxidative stress and apoptosis in } \\
\text { inflammatory disease [20] }\end{array}$ \\
\hline hsa-miR-192-5p & 1.14595 & 0.03 & $\begin{array}{l}\text { Upregulated in ALS vs. MS [21] } \\
\text { Regulatory factor in AD [22] } \\
\text { Related to A-beta expression in cortical neurons } \\
\text { animal model [16] }\end{array}$ \\
\hline hsa-miR-320a-3p & -0.862674 & 0.03 & Downregulated in schizophrenia [23] \\
\hline hsa-miR-451a & 1.435193 & 0.02 & $\begin{array}{l}\text { Upregulated in RR [4] } \\
\text { Upregulated in YOAD [24] } \\
\text { Upregulated in depression [25] } \\
\text { Downregulated in ALS [15] } \\
\text { Downregulated in MDD [26] } \\
\text { Downregulated in AD [27] }\end{array}$ \\
\hline hsa-miR-486-5p & -1.332208 & 0.03 & $\begin{array}{l}\text { Upregulated (NC) in MS with low BPV [19] } \\
\text { Upregulated in HD [28] }\end{array}$ \\
\hline hsa-miR-501-3p & -1.562031 & 0.002 & $\begin{array}{l}\text { Downregulated in sera AD [29] } \\
\text { Upregulated in brain tissue-progression [29] }\end{array}$ \\
\hline hsa-miR-576-5p & 1.74505 & 0.004 & $\begin{array}{l}\text { Upregulated in Relapse MS and ON vs. HC [30] } \\
\text { Downregulated in NMOSD [30] } \\
\text { Downregulated in active inflammation [31] }\end{array}$ \\
\hline hsa-miR-744-5p & -0.817595 & 0.04 & \\
\hline hsa-miR-1275 & -1.241061 & 0.01 & \\
\hline hsa-miR-4742-3p & 1.418434 & 0.03 & Downregulated in ASD [32] \\
\hline hsa-miR-548o-3p & 1.391054 & 0.03 & \\
\hline
\end{tabular}

Abbreviations: $\mathrm{FC}$ = fold change; $\mathrm{AD}=$ Alzheimer's disease; FTD = frontotemporal dementia; HC = healthy controls; $\mathrm{ADHD}=$ attention deficit hyperactive disorders; $\mathrm{SPMS}$ = secondary progressive multiple sclerosis; ALS = amyotrophic lateral sclerosis; PPMS = primary progressive multiple sclerosis; PedMS = pediatric multiple sclerosis; $\mathrm{BD}=$ bipolar disorder; RRMS = relapsing remitting multiple sclerosis; $\mathrm{ASD}=$ autism spectrum disorders; $\mathrm{MDD}=$ major depressive disorders; HD = Huntington's disease; NMOSD = neuromyelitis optica spectrum disorders. 
The analysis of mRNA expression from RNA-Seq data identified 64 DE genes (adjusted $p$-value $<0.05$, absolute log2 fold change $>1$ ). The DE miRNAs and genes were used for the miRNA-target analysis, under the assumption that changes in miRNA expression may influence the expression of their target/s. This analysis uncovered 58 predicted and/or validated miRNA-target pairs, including 23 target genes (Figure 1, Supplementary Table S2); most of them were genes already reported associated with several neuropsychiatric and neurodegenerative disorders, such as TBL1XR1 (targeted by miR-576-5p, miR-26b-5p, miR-182-5p, miR-451a, miR-4742-3p, miR-548o-3p), SRCAP (by miR-127-3p, miR-1275, miR-320a-3p, miR-486-5p, miR-744-5p) and GMFB (targeted by miR-182-5p, miR-548o-3p), as discussed below.

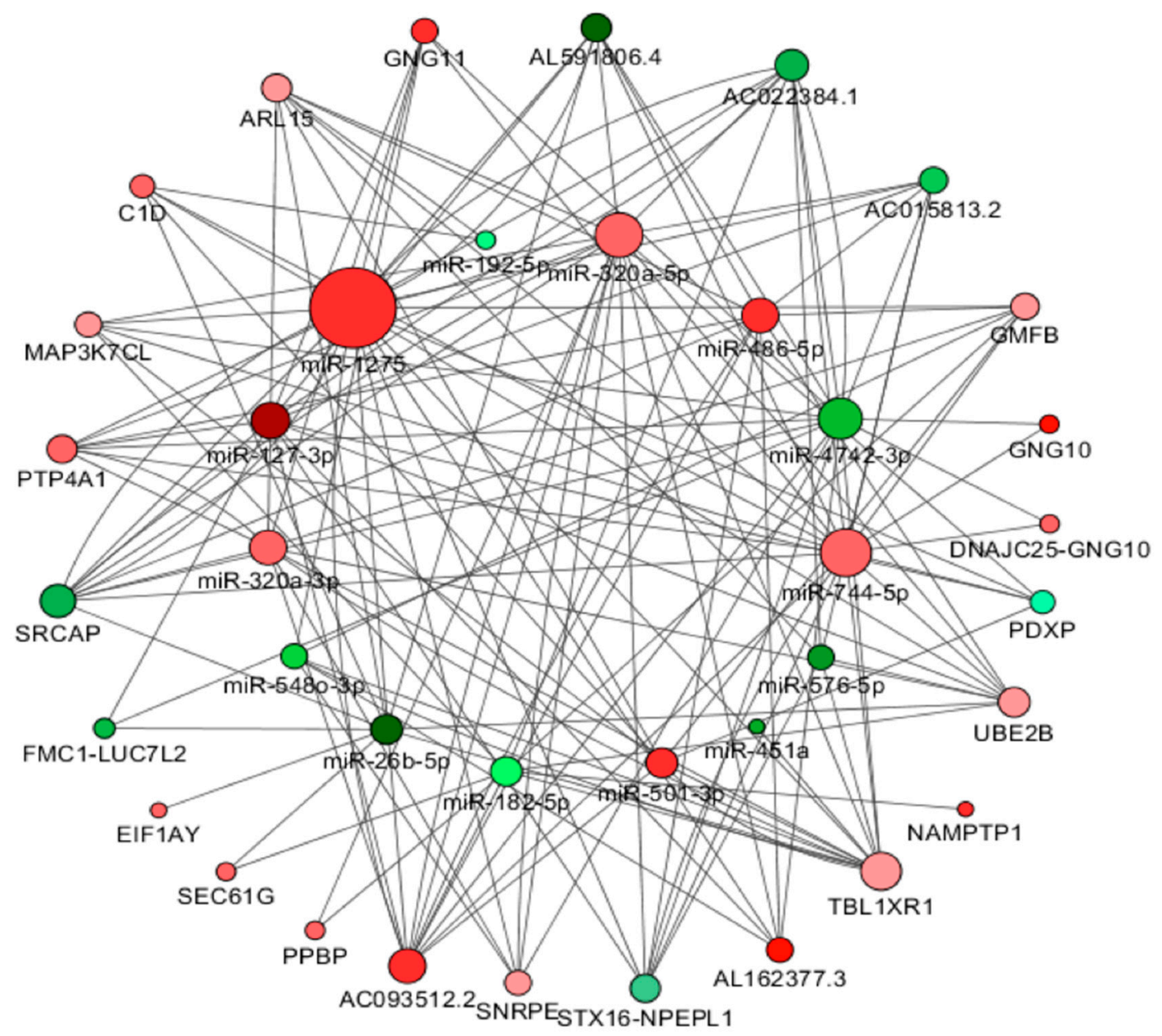

Figure 1. Graphical representation of miRNA-target genes interaction network using Cytoscape v3.7.2. The node intensity color is proportional to the log2 fold change values in the DE analysis (red: under-regulated; green: upregulated); the node size is proportional to the number of miRNA/mRNA connections. Please note that only downregulated genes were selected as targets of upregulated miRNAs (in the lower semicircle) and vice versa for downregulated miRNAs (in the upper semicircle).

No molecular pathways involving the most targeted genes survived the adjustment for multiple data; the only trend to significance was obtained by the KEGG chemokine signaling pathway that enclosed the genes GNG10, GNG11 and PPBB ( $p=0.034$, adjusted $p>0.05$ ).

\section{Discussion}

The possibility that miRNA pathways (including their mRNA gene targets) are involved in the modulation of MS during the developmental age carries the chance to actively interfere with novel 
and selective therapeutic strategies in order to prevent detrimental effects due to the progression of the disease or its disabling symptoms like the cognitive impairment. In the same direction, genetic variants (SNPs) within the genes coding for suggestive miRNAs or located in a miRNA-binding site of a target gene were evaluated as well, following the suggestion that they may impact the "normal" miRNA functions [33].

The hypothesis that there may be a molecular signature associated with the cognitive dysfunctions also in PedMS is more than plausible [7]. Several pieces of evidence also reported significant changes of selective miRNA/mRNA expression under the treatment available for MS, such as IFN $\beta$, one of the first approved DMTs since 1996, in the adult MS population [34]. These data, together with the numerous clinical evidences showing significant improvement of the MS cognitive performances under the IFN $\beta$ therapy [35], suggested that novel therapeutic strategies should be considered, with the final aim to target the dysregulated molecular pathways possibly identified during the MS cognitive performances.

Unfortunately, the small number of PedMS patients available for this further evaluation did not allow us to reach conclusive findings on this hypothesis, even in the evaluation of possible interference of the concomitant IFN $\beta$ in both the transcriptomic and the cognitive profiles of the studied PedMS cohort. However, in our view, several useful pieces of information were provided as well.

First of all, the neuropsychiatric evaluation showed that over an interval of 1-year, in the domains of attention and information processing speed, visual-spatial memory, executive functioning and expressive language, results were more compromised in the PedMS subjects than in the general MS population [36,37]. It is also worthy to note that for some other cognitive tests, the follow-ups registered slight improvements in the correspondent functions, without any concomitant cognitive rehabilitation, confirming once more that the interval for performing longitudinal investigation should be longer to avoid any interferences due to learning curve processing, especially in younger MS patients, as reported in other investigations [38].

Looking at the molecular results, our data demonstrated that the two time points differed significantly in the expression of 13 miRNAs. Among them, it is worthwhile to note that the expressions of miR-182-5p and miR-320a(-3p) were preliminarily associated with cognitive dysfunctions in the original cohort of 19 PedMS patients [7], whereas those of miR-26b-5p, miR-192-5p, miR-451a, miR-486-5 $p$ and miR-576-5 $p$ were already mentioned in adult MS populations $[4,13,19,21]$. Some of these significant miRNAs were reported jointly dysregulated in previous analyses, as they were part of common molecular pathways; this was observed, e.g., for miR-26b-5p, miR-182-5p and miR-451a in ALS [15]. Further investigations in larger sample sizes and possibly over a reasonably longer interval, as well as functional studies in MS and other neurodegenerative diseases, will shed light on the possibility that these significant miRNAs may be considered markers of some clinical changes over time.

Other intriguing tips derived from the analysis of mRNA expressions that led to several target genes of interest, some of which were already reported as associated with diseases that impair the cognitive performances. We cannot speculate on these preliminary results either, since they also suffer for the same weaknesses of the small-RNA data, as summarized below. However, in our view, they might be considered as key actors of a more complex molecular pathway underlying the cognitive functions that, especially in MS, still needs to be disentangled. For example, the most influenced gene (targeted by 6 miRNAs) is the transducing beta-like 1X-linked receptor 1 (TBL1XR1), which has been found associated with autism [39], mental retardation and disorders of neurodevelopment [40]. Five miRNAs targeted the Snf2 related CREBBP activator protein gene (SRCAP) that was found implicated in a rare form of $A D$ [41]. Interestingly, SRCAP impacts the transcription of CREB, involved with its transcription factors in memory retention and consolidation by hippocampal neurogenesis. Finally, although targeted only by two miRNAs, we would direct attention to the glia maturation factor beta gene (GMFB), a growth and differentiation factor for both glia and neurons, since it has been considered as a candidate therapeutic target for both neuroinflammatory and neurodegenerative diseases, given its role in mediating apoptosis and neuroinflammation [42]. 
Limitations of the study have been mostly already mentioned; despite the efforts of the investigators and the high motivations of the PedMS patients and their families during the first time period, only some of them were available for the follow-up. A longer interval would had been preferred for other inclusions, as well as for revealing further changes in the cognitive performances; however, this time extension was not possible due to several technical reasons (related to the incoming deadline of the financed project). Another unfortunate event was that we were not able to examine the second set of MRI scans, so we could not verify the associations between the miRNA expressions and the regional volumetric measurements of the brain, together with the molecular data, as we did at the baseline [7].

On the other hand, this strategy provided a unique opportunity to analyze simultaneously for the first time the miRNAs and their targeted mRNAs in a selected pediatric population of MS patients, which was confirmed as an amazing and reliable source of data and information. In fact, the study of miRNome and Targetome in pediatric patients enabled us to understand how genetic dysregulation during the developmental age could lead to autoimmune disorders and how a differential genetic expression may represent a substrate of the phenotype heterogeneity observed during the MS lifespan. Since children with MS can be considered environmentally naïve, we believe that their genetic load may provide more significant information than adult patients, especially about those factors that modulate their phenotypes.

Further investigations and collaborative efforts will be critical, as well as comparisons with other cognitive disorders of developmental ages, in order to test the possibility that they may share some of the molecular pathways implicated in cognitive dysfunctions.

Supplementary Materials: The following are available online at http://www.mdpi.com/2076-3417/10/22/8274/s1, Figure S1: Multidimensional scaling plot of Dispersion Index in longitudinal miRNA expressions, Table S1: Spearman's correlations between miRNA expressions and scores obtained at the individual cognitive tests, Table S2: Significant miRNAs/mRNAs pairs resulted from the analysis.

Author Contributions: M.L. conceived and designed the experiments, performed the neurological exams of the patients, supervised the study and wrote the manuscript; N.N. performed the molecular experiments and the preliminary analysis of the data, and significantly contribute to the manuscript; R.G.V. performed the neuropsychological exams of the patients; A.C. and F.L. performed the bioinformatics/biostatistics analysis of the data with the contribution of S.L.; as Chief of the MS Outpatients Clinic, M.T. supervised the clinical data. All authors have read and agreed to the published version of the manuscript.

Funding: This research was funded by Fondazione Italiana Sclerosi Multipla (FISM), Grant no. 2014/R/10.

Acknowledgments: The Authors are grateful to the MS patients and their families who kindly agreed to be part of the project.

Conflicts of Interest: Authors declare no conflicts of interests.

\section{References}

1. Compston, A.; Coles, A.J. Multiple sclerosis. Lancet 2008, 372, 1502-1517. [CrossRef]

2. Olsson, T.; Barcellos, L.F.; Alfredsson, L. Interactions between genetic, lifestyle and environmental risk factors for multiple sclerosis. Nat. Rev. Neurol. 2017, 13, 25-36. [CrossRef] [PubMed]

3. Banwell, B. Multiple sclerosis in children. Handb. Clin. Neurol. 2014, 122, 427-441. [CrossRef] [PubMed]

4. Ebrahimkhani, S.; Vafaee, F.; Young, P.E.; Hur, S.S.J.; Hawke, S.; Devenney, E.; Beadnall, H.; Barnett, M.H.; Suter, C.M.; Buckland, M.E. Exosomal microRNA signatures in multiple sclerosis reflect disease status. Sci. Rep. 2017, 7, 1-10. [CrossRef]

5. Liguori, M.; Nuzziello, N.; Licciulli, F.; Consiglio, A.; Simone, M.; Viterbo, R.G.; Creanza, T.M.; Ancona, N.; Tortorella, C.; Margari, L.; et al. Combined microRNA and mRNA expression analysis in pediatric multiple sclerosis: An integrated approach to uncover novel pathogenic mechanisms of the disease. Hum. Mol. Genet. 2018, 27, 66-79. [CrossRef]

6. Nuzziello, N.; Vilardo, L.; Pelucchi, P.; Consiglio, A.; Liuni, S.; Trojano, M.; Liguori, M. Investigating the Role of MicroRNA and Transcription Factor Co-regulatory Networks in Multiple Sclerosis Pathogenesis. Int. J. Mol. Sci. 2018, 19, 3652. [CrossRef] 
7. Liguori, M.; Nuzziello, N.; Simone, M.; Amoroso, N.; Viterbo, R.G.; Tangaro, S.; Consiglio, A.; Giordano, P.; Bellotti, R.; Trojano, M. Association between miRNAs expression and cognitive performances of Pediatric Multiple Sclerosis patients: A pilot study. Brain Behav. 2019, 9, e01199. [CrossRef]

8. Kurtzke, J.F. Rating neurologic impairment in multiple sclerosis: An expanded disability status scale (EDSS). Neurology 1983, 33, 1444. [CrossRef]

9. Amato, M.P.; Goretti, B.; Ghezzi, A.; Lori, S.; Zipoli, V.; Moiola, L.; Falautano, M.; De Caro, M.F.; Viterbo, R.; Patti, F.; et al. Cognitive and psychosocial features in childhood and juvenile MS: Two-year follow-up. Neurology 2010, 75, 1134-1140. [CrossRef]

10. Chang, W.-S.; Wang, Y.-H.; Zhu, X.-T.; Wu, C.-J. Genome-Wide Profiling of miRNA and mRNA Expression in Alzheimer's Disease. Med. Sci. Monit. 2017, 23, 2721-2731. [CrossRef]

11. Denk, J.; Oberhauser, F.; Kornhuber, J.; Wiltfang, J.; Fassbender, K.; Schroeter, M.L.; Volk, A.E.; Diehl-Schmid, J.; Prudlo, J.; Danek, A.; et al. Specific serum and CSF microRNA profiles distinguish sporadic behavioural variant of frontotemporal dementia compared with Alzheimer patients and cognitively healthy controls. PLoS ONE 2018, 13, e0197329. [CrossRef] [PubMed]

12. Sánchez-Mora, C.; Artigas, M.S.; Garcia-Martínez, I.; Pagerols, M.; Rovira, P.; Richarte, V.; Corrales, M.; Fadeuilhe, C.; Padilla, N.; De La Cruz, X.; et al. Epigenetic signature for attention-deficit/hyperactivity disorder: Identification of miR-26b-5p, miR-185-5p, and miR-191-5p as potential biomarkers in peripheral blood mononuclear cells. Neuropsychopharmacology 2019, 44, 890-897. [CrossRef] [PubMed]

13. Sanders, K.A.; Benton, M.C.; Lea, R.A.; Maltby, V.E.; Agland, S.; Griffin, N.; Scott, R.J.; Tajouri, L.; Lechner-Scott, J. Next-generation sequencing reveals broad down-regulation of microRNAs in secondary progressive multiple sclerosis CD4+ T cells. Clin. Epigenet. 2016, 8, 87. [CrossRef] [PubMed]

14. Chen, J.; Qi, Y.; Liu, C.-F.; Lu, J.-M.; Shi, J.; Shi, Y. MicroRNA expression data analysis to identify key miRNAs associated with Alzheimer's disease. J. Gene Med. 2018, 20, e3014. [CrossRef] [PubMed]

15. Liguori, M.; Nuzziello, N.; Introna, A.; Consiglio, A.; Licciulli, F.; D’Errico, E.; Scarafino, A.; Distaso, E.; Simone, I.L. Dysregulation of MicroRNAs and Target Genes Networks in Peripheral Blood of Patients With Sporadic Amyotrophic Lateral Sclerosis. Front. Mol. Neurosci. 2018, 11, 288. [CrossRef] [PubMed]

16. Dursun, E.; Candaş, E.; Yılmazer, S.; Gezen-Ak, D. Amyloid Beta 1-42 Alters the Expression of miRNAs in Cortical Neurons. J. Mol. Neurosci. 2019, 67, 181-192. [CrossRef]

17. Piscopo, P.; Grasso, M.; Puopolo, M.; D'Acunto, E.; Talarico, G.; Crestini, A.; Gasparini, M.; Campopiano, R.; Gambardella, S.; Castellano, A.E.; et al. Circulating miR-127-3p as a Potential Biomarker for Differential Diagnosis in Frontotemporal Dementia. J. Alzheimer's Dis. 2018, 65, 455-464. [CrossRef]

18. Boese, A.S.; Saba, R.; Campbell, K.; Majer, A.; Medina, S.; Burton, L.; Booth, T.F.; Chong, P.; Westmacott, G.R.; Dutta, S.M.; et al. MicroRNA abundance is altered in synaptoneurosomes during prion disease. Mol. Cell. Neurosci. 2016, 71, 13-24. [CrossRef]

19. Regev, K.; Healy, B.C.; Khalid, F.; Paul, A.; Chu, R.; Tauhid, S.; Tummala, S.; Diaz-Cruz, C.; Raheja, R.; Mazzola, M.A.; et al. Association Between Serum MicroRNAs and Magnetic Resonance Imaging Measures of Multiple Sclerosis Severity. JAMA Neurol. 2017, 74, 275-285. [CrossRef]

20. Qin, S.-B.; Peng, D.-Y.; Lu, J.-M.; Ke, Z.-P. MiR-182-5p inhibited oxidative stress and apoptosis triggered by oxidized low-density lipoprotein via targeting toll-like receptor 4. J. Cell. Physiol. 2018, 233, 6630-6637. [CrossRef]

21. Raheja, R.; Regev, K.; Healy, B.C.; Mazzola, M.A.; Beynon, V.; Von Glehn, F.; Paul, A.; Diaz-Cruz, C.; Gholipour, T.; Glanz, B.I.; et al. Correlating serum micrornas and clinical parameters in amyotrophic lateral sclerosis. Muscle Nerve 2018, 58, 261-269. [CrossRef] [PubMed]

22. Rahman, R.; Islam, T.; Turanli, B.; Zaman, T.; Faruquee, H.M.; Rahman, M.; Mollah, N.H.; Nanda, R.K.; Arga, K.Y.; Gov, E.; et al. Network-based approach to identify molecular signatures and therapeutic agents in Alzheimer's disease. Comput. Biol. Chem. 2019, 78, 431-439. [CrossRef] [PubMed]

23. Wang, Y.; Wang, J.; Guo, T.; Peng, Y.; Wang, K.; Bai, K.; Huang, Y. Screening of schizophrenia associated miRNAs and the regulation of miR-320a-3p on integrin $\beta 1$. Medicine 2019, 98, e14332. [CrossRef] [PubMed] 
24. McKeever, P.M.; Schneider, R.; Taghdiri, F.; Weichert, A.; Multani, N.; Brown, R.A.; Boxer, A.L.; Karydas, A.; Miller, B.; Robertson, J.; et al. MicroRNA Expression Levels Are Altered in the Cerebrospinal Fluid of Patients with Young-Onset Alzheimer's Disease. Mol. Neurobiol. 2018, 55, 8826-8841. [CrossRef]

25. Camkurt, M.A.; Acar Şenel, T.; Coşkun, S.; Gunes, M.L.; Güneş, S.; Yılmaz, M.F.; Görür, A.; Tamer, L. Comparison of plasma MicroRNA levels in drug naive, first episode depressed patients and healthy controls. J. Psychiatr. Res. 2015, 69, 67-71. [CrossRef] [PubMed]

26. Wan, Y.; Liu, Y.; Wang, X.; Wu, J.; Liu, K.; Zhou, J.; Liu, L.; Zhang, C. Identification of Differential MicroRNAs in Cerebrospinal Fluid and Serum of Patients with Major Depressive Disorder. PLoS ONE 2015, 10, e0121975. [CrossRef]

27. Gámez-Valero, A.; Campdelacreu, J.; Vilas, D.; Ispierto, L.; Reñé, R.; Álvarez, R.; Armengol, M.P.; Borràs, F.E.; Beyer, K. Exploratory study on microRNA profiles from plasma-derived extracellular vesicles in Alzheimer's disease and dementia with Lewy bodies. Transl. Neurodegener. 2019, 8, 1-17. [CrossRef]

28. Hoss, A.G.; Bs, V.N.L.; Frank, S.; Hadzi, T.C.; Myers, R.H.; Dsc, J.C.L. Study of plasma-derived miRNAs mimic differences in Huntington's disease brain. Mov. Disord. 2015, 30, 1961-1964. [CrossRef]

29. Hara, N.; Kikuchi, M.; Miyashita, A.; Hatsuta, H.; Saito, Y.; Kasuga, K.; Murayama, S.; Ikeuchi, T.; Kuwano, R. Serum microRNA miR-501-3p as a potential biomarker related to the progression of Alzheimer's disease. Acta Neuropathol. Commun. 2017, 5, 1-9. [CrossRef]

30. Chen, J.; Zhu, J.; Wang, Z.; Yao, X.; Wu, X.; Liu, F.; Zheng, W.; Li, Z.; Lin, A. MicroRNAs Correlate with Multiple Sclerosis and Neuromyelitis Optica Spectrum Disorder in a Chinese Population. Med. Sci. Monit. 2017, 23, 2565-2583. [CrossRef]

31. Mansouri, L.; Lundwall, K.; Moshfegh, A.; Jacobson, S.H.; Lundahl, J.; Spaak, J. Vitamin D receptor activation reduces inflammatory cytokines and plasma MicroRNAs in moderate chronic kidney disease-A randomized trial. BMC Nephrol. 2017, 18, 1-7. [CrossRef] [PubMed]

32. Ander, B.P.; Barger, N.; Stamova, B.; Sharp, F.R.; Schumann, C.M. Atypical miRNA expression in temporal cortex associated with dysregulation of immune, cell cycle, and other pathways in autism spectrum disorders. Mol. Autism 2015, 6, 37. [CrossRef] [PubMed]

33. Rhead, B.; Shao, X.; Graves, J.S.; Chitnis, T.; Waldman, A.T.; Lotze, T.; Schreiner, T.; Belman, A.; Krupp, L.; Greenberg, B.M.; et al. mi RNA contributions to pediatric-onset multiple sclerosis inferred from GWAS. Ann. Clin. Transl. Neurol. 2019, 6, 1053-1061. [CrossRef] [PubMed]

34. Fattahi, M.; Rezaei, N.; Nematalahi, F.S.; Shaygannejad, V.; Fouladi, S.; Karimi, L.; Fathi, F.; Dehghani, L.; Mirmosayyeb, O.; Eskandari, N. MicroRNA-29b variants and MxA expression change during interferon beta therapy in patients with relapsing-remitting multiple sclerosis. Mult. Scler. Relat. Disord. 2019, 35, 241-245. [CrossRef]

35. Benešová, Y.; Tvaroh, A. Cognition and fatigue in patients with relapsing multiple sclerosis treated by subcutaneous interferon $\beta$-1a: An observational study SKORE. Ther. Adv. Neurol. Disord. 2017, 10, 18-32. [CrossRef]

36. Nunan-Saah, J.H.; Paulraj, S.R.; Waubant, E.; Krupp, L.B.; Gomez, R.G. Neuropsychological correlates of multiple sclerosis across the lifespan. Mult. Scler. J. 2015, 21, 1355-1364. [CrossRef]

37. Sokolov, A.A.; Grivaz, P.; Bove, R. Cognitive Deficits in Multiple Sclerosis: Recent Advances in Treatment and Neurorehabilitation. Curr. Treat. Options Neurol. 2018, 20, 53. [CrossRef]

38. Öztürk, Z.; Gucuyener, K.; Acar, A.; Şebnem, S.; Konuşkan, G.D.; Konuşkan, B.; Dikmen, A.U.; Anlar, B. Cognitive functions in pediatric multiple sclerosis: 2-years follow-up. Neurol. Res. 2020, 42, $159-163$. [CrossRef]

39. O'Roak, B.J.; Vives, L.; Fu, W.; Egertson, J.D.; Stanaway, I.B.; Phelps, I.G.; Carvill, G.; Kumar, A.; Lee, C.; Ankenman, K.; et al. Multiplex Targeted Sequencing Identifies Recurrently Mutated Genes in Autism Spectrum Disorders. Science 2012, 338, 1619-1622. [CrossRef]

40. Yamamoto, T.; Imaizumi, T.; Yamamoto-Shimojima, K.; Lu, Y.; Yanagishita, T.; Shimada, S.; Chong, P.F.; Kira, R.; Ueda, R.; Ishiyama, A.; et al. Genomic backgrounds of Japanese patients with undiagnosed neurodevelopmental disorders. Brain Dev. 2019, 41, 776-782. [CrossRef] 
41. Vardarajan, B.N.; Tosto, G.; Lefort, R.; Yu, L.; Bennett, D.A.; De Jager, P.L.; Barral, S.; Reyes-Dumeyer, D.; Nagy, P.L.; Lee, J.H.; et al. Ultra-rare mutations in SRCAP segregate in Caribbean Hispanic families with Alzheimer disease. Neurol. Genet. 2017, 3, e178. [CrossRef] [PubMed]

42. Fan, J.; Fong, T.; Chen, X.; Chen, C.; Luo, P.; Xie, H. Glia maturation factor- $\beta$ : A potential therapeutic target in neurodegeneration and neuroinflammation. Neuropsychiatr. Dis. Treat. 2018, 14, 495-504. [CrossRef] [PubMed]

Publisher's Note: MDPI stays neutral with regard to jurisdictional claims in published maps and institutional affiliations.

(C) 2020 by the authors. Licensee MDPI, Basel, Switzerland. This article is an open access article distributed under the terms and conditions of the Creative Commons Attribution (CC BY) license (http://creativecommons.org/licenses/by/4.0/). 